\title{
UM ESTUDO DA INFLUÊNCIA DA GESTÃO DE PESSOAS NO DESEMPENHO DO TRABALHADOR E NA MELHORIA DA QUALIDADE
}

\author{
Crislaine Carvalho ${ }^{1}$ \\ Edicarlos Geraldo dos Santos Junior ${ }^{2}$ \\ Fabiana Amaral de Azevedo Sene Silva ${ }^{3}$
}

Resumo: A qualidade é uma das principais preocupações presentes dentro das organizações, e estas estão sempre à procura de ferramentas que possam auxiliar nesse processo. A influência da gestão de pessoas no desempenho do trabalhador pode ser um diferencial para as empresas no mercado competitivo. Este trabalho tem a finalidade de apresentar o relacionamento entre a gestão de pessoas e a gestão da qualidade e seus reflexos no processo de melhoria contínua. Nesse contexto, foi feita uma revisão bibliográfica da evolução histórica da qualidade e os reflexos da gestão de pessoas nesse processo. Foi estudado também uma evolução do termo Gestão de Pessoas e suas diversas nomenclaturas adotadas ao longo do tempo, e as influências dessas nomenclaturas no relacionamento com os funcionários. Essa pesquisa trouxe resultados positivos a respeito da influência da gestão de pessoas na melhoria da qualidade, mostrando que os interesses da empresa e dos funcionários podem sim caminhar juntos, desde que ambos os lados estejam satisfeitos, o que confirmou a hipótese inicial desse trabalho.

Palavras-chave: Gestão de pessoas; Qualidade; Melhoria contínua; Competitividade; Valorização.

\footnotetext{
${ }^{1}$ Engenharia de Produção/Centro Universitário de Itajubá - FEPI, Brasil. E-mail: crislainecrk@gmail.com.

2 Engenharia de Produção/Centro Universitário de Itajubá - FEPI, Brasil. E-mail: edicarlos.jr.santos@gmail.com.

${ }^{3}$ Engenharia de Produção/Centro Universitário de Itajubá - FEPI, Brasil. E-mail: fabianasenne@hotmail.com.
} 